\title{
Endometrial Ice Application Prior to Embryo Transfer in Cases of Recurrent Unexplained In-Vitro Fertilization Failure: A Pilot Study
}

\author{
Ahmed S. El-Halwagy, Adel A. Al-Gergawy \\ Lecturer of Obstetrics and Gynecology, Faculty of Medicine, Tanta University, Tanta, Egypt \\ Email: halwagy22@yahoo.com
}

How to cite this paper: El-Halwagy, A.S. and Al-Gergawy, A.A. (2017) Endometrial Ice Application Prior to Embryo Transfer in Cases of Recurrent Unexplained In-Vitro Fertilization Failure: A Pilot Study. Open Journal of Obstetrics and Gynecology, 7, 167-173.

https://doi.org/10.4236/ojog.2017.72018

Received: January 5, 2017

Accepted: February 5, 2017

Published: February 8, 2017

Copyright $\odot 2017$ by authors and Scientific Research Publishing Inc. This work is licensed under the Creative Commons Attribution International License (CC BY 4.0).

http://creativecommons.org/licenses/by/4.0/

(c) (i) Open Access

\begin{abstract}
Introduction: This prospective pilot study was done to get preliminary data about a new technique of inflecting endometrial injury in order to improve implantation rate in IVF cases. Patients and methods: 60 patients were enrolled and randomly distributed into 3 groups. Each group included 20 patients. This study was conducted in the Egyptian consultants for infertility management and IVF center Tanta-Egypt, in the period from January 2015 to March 2016. In group A (study group 1), the 20 patients included in this group underwent endometrial scratching once at day 21 of menstrual cycle in the cycle prior to ET by a $4 \mathrm{~mm}$ disposable Karman's cannula inserted through the cervical os. While in group B (study group 2), the 20 patients underwent the new technique of endometrial Ice bars application for 10 minutes at day 7 of the embryo transfer cycle to inflect the physical trauma required for the change in the endometrial receptivity. In Group C (control group), the 20 patients didn't receive any extra action rather than the ordinary preparation for embryo transfer. The primary outcome measures of the study were the clinical pregnancy rate and the number of pregnancies that exceeded 14 weeks of gestation. The secondary outcome measures were multiple pregnancy and miscarriage ratios. Results: The results of this pilot study shows a ( $>14$ weeks) pregnancy rate which is equal in the endometrial icing $(30 \% \mathrm{n}=6 / 20)$ and endometrial scratching group $(30 \% \mathrm{n}=6 \backslash 20)$. The $>14$ weeks pregnancy rate in both groups is higher than the control group $(25 \% n=5 / 20)$. The small number of patients in the pilot study may explain the difference to be statistically non-significant. The abortion rate was $33.3 \%(\mathrm{n}=3 / 9)$ in the scratching group and $25 \%(n=2 / 8)$ in the icing group and $16.6 \%(n=1 / 5)$ in the control group. The multiple pregnancy rate was $16.6 \%(\mathrm{n}=1 / 6)$ in the scratching group and $33.3 \%(n=2 / 6)$ in the icing group and $20 \%(n=1 / 5)$ in the control group. Conclusion: Endometrial icing is a new technique of endometrial injury which deserves more studies to test its efficacy in improving embryo im-
\end{abstract}


plantation and to test its safety.

\section{Keywords}

Endometrial Icing, Endometrial Scratching, Implantation Failure, In Vitro Fertilization (IVF)

\section{Introduction}

Assisted reproductive techniques have solved many infertility problems, but not implantation which is still considered the main obstacle to IVF success. The uterine receptivity is known as the implantation window which coincides with the mid secretory period [1]. Hatching, opposition, adherence, penetration and finally invasion are the steps needed for the blastocyst for successful implantation to happen. And the endometrium should be also prepared by estrogen and progesterone and needs to be in time [2]. Barash et al. in 2003 was the very first researchers who studied the effect of endometrial injury on implantation. They concluded that endometrial scratching done at different phases of the endometrial cycles is associated with higher pregnancy rate after IVF [3]. They also postulated that trauma to the endometrium may lead to release of growth factors and inflammatory cytokines during the process of wound healing, which may assist implantation. This improvement in implantation after endometrial injury can be explained by 3 suggestions. First postulation is the increased decidualization in response to local injury [4]. Second hypothesis, the considerable increase in the release of cytokines, interleukins, growth factors, macrophages, and dendritic cells with endometrial healing, all of which are of benefit in the process of implantation [4] [5]. Third is the accelerated maturation of the endometrium in response to controlled ovarian stimulation during ART [6]. However there is still a lot of contradiction about the benefits of endometrial injury. In addition, there is no agreement on the degree, method and number of injuries to be performed, the interval between the procedure and embryo transfer cycle [7].

There is a question which flashed in our minds, can any physical injury to the endometrium produce a similar effect to scratch and improve implantation results. In this pilot study, we try to get provisional answer to this question, and to get an experience of this new technique to build upon in the future studies.

\section{Patients and Methods}

This study was conducted in the Egyptian consultants for infertility management and IVF center Tanta-Egypt, in the period from January 2015 to March 2016. In this prospective pilot study 60 patients were enrolled in the study after application of inclusion and exclusion criteria.

All women were thoroughly informed about the study aims and through discussion about the procedure, associated benefits and risks and signed written consents. 


\subsection{Inclusion Criteria}

The study inclusion criteria were patients who is going to perform a cryo-embryo transfer of 3 grade 4AA blastocysts with age $<35$ years, good ovarian reserve (Anti-Mullerian Hormone $[\mathrm{AMH}]>1 \mathrm{ng} / \mathrm{ml}$ ), no uterine manipulation within last 3 months (e.g., hysteroscopy, myomectomy etc.), with a prior unexplained one implantation failure in ICSI cycle.

\subsection{Exclusion Criteria}

The exclusion criteria were age $>35$ years with confounding factors (e.g. poor ovarian reserve), Grade III and IV endometriosis, history of septal resection, adhesiolysis and abnormal uterine cavity. Common causes of implantation failure as diabetes mellitus, hypertension, autoimmune diseases, distorted endometrial cavity, suspected or diagnosed hydrosalpinx, congenital and acquired thrombophilia, vitamin D deficiency, and poor quality embryos should be rolled out.

\subsection{Baseline Examination}

All patients were assessed by history taking, clinical examinations and were investigated by routine laboratory investigations before the study embryo transfer cycle.

Women who satisfied the inclusion criteria were randomized to one of the three study groups according to a sequence of computer generated block-random numbers.

In group A (study group 1) the 20 patients included in this group underwent endometrial scratching once at day 21 of menstrual cycle in the cycle prior to ET. Anterior and posterior walls of endometrium were scratched gently by a 4 mm disposable Karman's cannula inserted through the cervical os. While in group B (study group 2) the 20 patients underwent the new technique of endometrial Ice bars application for 10 minutes at day 7 of the embryo transfer cycle. The ice bars used in the study was a sterile water ice bars $5 \mathrm{~cm}$ in length $0.5 \mathrm{~cm}$ in diameter to be inserted intrauterine, with new one insertion every 2 minutes to ensure 10 minutes of actual exposure of the endometrium to zero temperature to inflect the physical trauma required for the change in the endometrial receptivity. In Group C (control group) the 20 patients didn't receive any extra action rather than the ordinary preparation for embryo transfer.

All the patients in the three groups were prepared for cryo embryo transfer by receiving $2 \mathrm{mg}$ estradiol valerate daily from day 2 of the menstrual flow with addition of $100 \mathrm{mg}$ progesterone daily IM injection from day 15 with embryo transfer on day 19 of three 4 AA blastocysts.

The primary outcome measures of the study were the clinical pregnancy rate and the number of pregnancies that exceeded 14 weeks of gestation.

The secondary outcome measures were multiple pregnancy and miscarriage ratios.

All statistics were performed using Minitab Ver. 17 (Minitab Inc., USA) we used one way ANOVA and Chi square tests as shown below. 


\section{Results}

On comparing the demographic data of the study groups (Table 1) there was no statistically significant difference using one way ANOVA test.

On comparing the (>14 weeks) pregnancy rate (Table 2 ) there was no statistically significant difference using Chi square test.

On comparing the abortion rate (Table 3 ) there was no statistically significant difference using Chi square test.

On comparing the multiple pregnancy rate (Table 4) there was no statistically significant difference using Chi square test.

Figure 1 shows a brief summary of the study results including pregnancy rate, abortion rate and multiple pregnancy rate.

Table 1. Comparison of the demographic data of the 3 groups.

\begin{tabular}{ccccc}
\hline & Group 1 scratching & Group 2 icing & Group 3 control & P value \\
\hline Age & $27.9 \pm 2.2$ & $28.7 \pm 3.0$ & $29.1 \pm 2.3$ & 0.356 \\
BMI & $25.4 \pm 4.8$ & $26.1 \pm 4.8$ & $26.3 \pm 3.9$ & 0.821 \\
\hline
\end{tabular}

Table 2. (>14 weeks) Pregnancy rate in the study groups.

\begin{tabular}{ccccc}
\hline Pregnancy reached 14 weeks & Scratching & Icing & Control \\
\hline +ve & N & 6 & 6 & 5 \\
& $\%$ & $30 \%$ & $30 \%$ & $25 \%$ \\
-ve & N & 14 & 14 & 17 \\
& $\%$ & $70 \%$ & $70 \%$ & $75 \%$ \\
Chi-square & $\mathrm{X}^{2}$ & & 0.166 & \\
& P-value & & 0.920 &
\end{tabular}

Table 3. Abortion rate.

\begin{tabular}{|c|c|c|c|c|}
\hline \multicolumn{2}{|l|}{ Abortion } & Scratching & Icing & Control \\
\hline \multicolumn{2}{|l|}{$\mathbf{N}$} & $3 / 9$ & $2 / 8$ & $1 / 6$ \\
\hline \multicolumn{2}{|l|}{$\%$} & $33.3 \%$ & $25.0 \%$ & $16.6 \%$ \\
\hline \multirow{2}{*}{ Chi-square } & $\mathrm{X}^{2}$ & & 0.314 & \\
\hline & $\mathrm{P}$-value & & 0.855 & \\
\hline
\end{tabular}

Table 4. Multiple pregnancy rate.

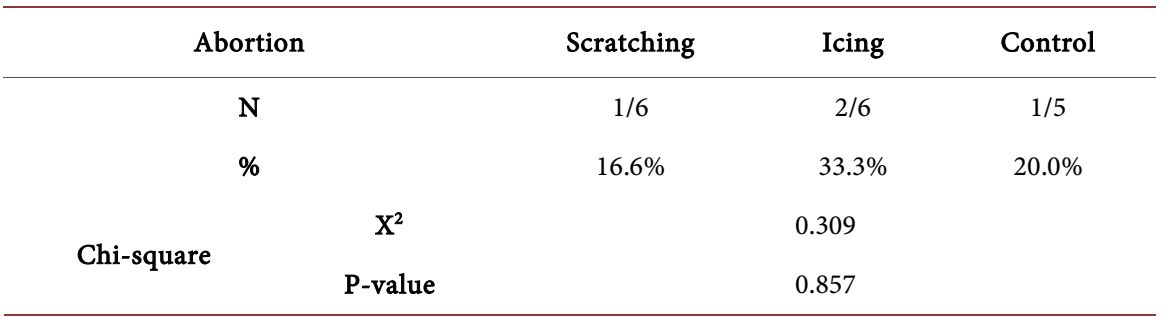




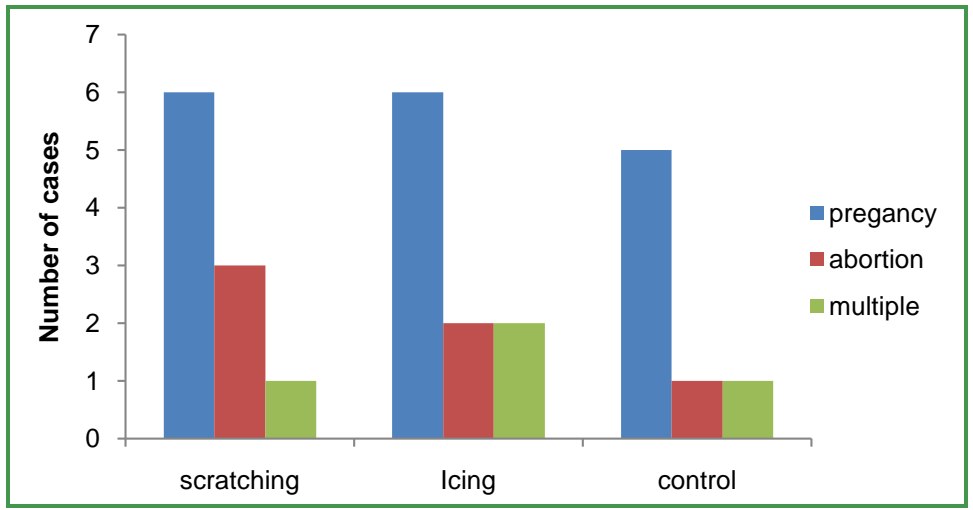

Figure 1. Summary of study results.

\section{Discussion}

Implantation of embryos in females with recurrent failure of implantation has been suggested to be improved by inflicting local endometrial injury. early nonrandomized trials showed a two folds increase in conception rates after endometrial injuries done at different phases of the menstrual cycle in women with prior failure of implantation [3] [8]. After that, many trials were performed on women with recurrent implantation failure. Most of these trials showed significant implantation rates improvement on doing the endometrial injury in the preceding cycle [2] [9] [10], while another trial showed no benefit of such a scratching procedure [11].

We have thought that may be any physical trauma could produce the same theoretical effects on the endometrium with the same improvement in implantation rate or perhaps better. Also inflicting physical trauma to the endometrium by ice application may produce more widespread effect on the endometrium than the localized effect of the scratching. At the same time exposure to ice seems to be an easy to promote idea to the patients.

The results of this pilot study shows a ( $>14$ weeks) pregnancy rate which is equal in the endometrial icing $(30 \%, n=6 / 20)$ and endometrial scratching group $(30 \%, n=6 / 20)$. The $>14$ weeks pregnancy rate in both groups is higher than the control group $(25 \%, \mathrm{n}=5 \backslash 20)$. The small number of patients in the pilot study may explain the difference to be statistically non significant.

The abortion rate was $33.3 \%(\mathrm{n}=3 / 9)$ in the scratching group and $25 \%(\mathrm{n}=$ $2 / 8)$ in the icing group and $16.6 \%(\mathrm{n}=1 / 5)$ in the control group. The multiple pregnancy rate was $16.6 \%(n=1 / 6)$ in the scratching group and $33.3 \%(n=2 / 6)$ in the icing group and $20 \%(\mathrm{n}=1 / 5)$ in the control group.

The results of this pilot study give an encouraging preliminary data to build upon and to go on to a study on a large number of patients to get a solid opinion about this new technique. Also the safety of this procedure couldn't be judged from this pilot study and needs a larger study.

\section{Conclusion}

Endometrial icing is a new technique of endometrial injury which deserves more 
studies to test its efficacy in improving embryo implantation and to test its safety.

\section{Declaration of Interest}

The authors report no conflicts of interest.

\section{References}

[1] Dekel, N., Gnainsky, Y., Granot, I., Racicot, K. and Mor, G. (2014) The Role of Inflammation for a Successful Implantation. American Journal of Reproductive Immunology, 72, 141-147. https://doi.org/10.1111/aji.12266

[2] Narvekar, S.A., Gupta, N., Shetty, N., Kottur, A., Srinivas, M. and Rao, K.A. (2010) Does Local Endometrial Injury in the Nontransfer Cycle Improve the IVF-ET Outcome in the Subsequent Cycle in Patients with Previous Unsuccessful IVF? A Randomized Controlled Pilot Study. Journal of Human Reproductive Sciences, 3, 15-19. https://doi.org/10.4103/0974-1208.63116

[3] Barash, A., Dekel, N., Fieldust, S., Segal, I., Schechtman, E. and Granot, I. (2003) Local Injury to the Endometrium Doubles the Incidence of Successful Pregnancies in Patients Undergoing in Vitro Fertilization. Fertility and Sterility, 79, 1317-1322. https://doi.org/10.1016/S0015-0282(03)00345-5

[4] Li, R. and Hao, G. (2009) Local Injury to the Endometrium: Its Effect on Implantation. Current Opinion in Obstetrics and Gynecology, 21, 236-239. https://doi.org/10.1097/GCO.0b013e32832a0654

[5] Gnainsky, Y., Granot, I., Aldo, P.B., Barash, A., Or, Y., Schechtman, E., et al. (2010) Local Injury of the Endometrium Induces an Inflammatory Response That Promotes Successful Implantation. Fertility and Sterility, 94, 2030-2036. https://doi.org/10.1016/j.fertnstert.2010.02.022

[6] Lass, A., Peat, D., Avery, S. and Brinsden, P. (1998) Histological Evaluation of Endometrium on the Day of Oocyte Retrieval after Gonadotrophin-Releasing Hormone Agonist-Follicle Stimulating Hormone Ovulation Induction for In-Vitro Fertilization. Human Reproduction, 13, 3203-3205. https://doi.org/10.1093/humrep/13.11.3203

[7] Simon, C. and Bellver, J. (2014) Scratching Beneath "The Scratching Case": Systematic Reviews and Meta-Analyses, the Back Door for Evidence-Based Medicine. Human Reproduction, 29, 1618-1621. https://doi.org/10.1093/humrep/deu126

[8] Raziel, A., Schachter, M., Strassburger, D., Bern, O., Ron-El, R. and Friedler, S. (2007) Favorable Influence of Local Injury to the Endometrium in Intracytoplasmic Sperm Injection Patients with High-Order Implantation Failure. Fertility and Sterility, 87, 198-201. https://doi.org/10.1016/j.fertnstert.2006.05.062

[9] Karimzadeh, M.A., Ayazi Rozbahani, M. and Tabibnejad, N. (2009) Endometrial Local Injury Improves the Pregnancy Rate Among Recurrent Implantation Failure Patients Undergoing in Vitro Fertilisation/Intra Cytoplasmic Sperm Injection: A Randomised Clinical Trial. The Australian New Zealand Journal of Obstetrics Gynaecology, 49, 677-680. https://doi.org/10.1111/j.1479-828X.2009.01076.x

[10] Gibreel, A., Badawy, A., El-Refai, W. and El-Adawi, N. (2013) Endometrial Scratching to Improve Pregnancy Rate in Couples with Unexplained Subfertility: A Randomized Controlled Trial. Journal of Obstetrics and Gynaecology Research, 39, 680-684. https://doi.org/10.1111/j.1447-0756.2012.02016.x

[11] Baum, M., Yerushalmi, G.M., Maman, E., Kedem, A., Machtinger, R., Hourvitz, A., 
et al. (2012) Does Local Injury to the Endometrium before IVF Cycle Really Affect Treatment Outcome? Results of a Randomized Placebo Controlled Trial. Gynecological Endocrinology, 28, 933-936. https://doi.org/10.3109/09513590.2011.650750

\section{Scientific Research Publishing}

Submit or recommend next manuscript to SCIRP and we will provide best service for you:

Accepting pre-submission inquiries through Email, Facebook, LinkedIn, Twitter, etc. A wide selection of journals (inclusive of 9 subjects, more than 200 journals)

Providing 24-hour high-quality service

User-friendly online submission system

Fair and swift peer-review system

Efficient typesetting and proofreading procedure

Display of the result of downloads and visits, as well as the number of cited articles Maximum dissemination of your research work

Submit your manuscript at: http://papersubmission.scirp.org/

Or contact ojog@scirp.org 